\title{
Correction to: Effects of secondary succession on soil fungal and bacterial compositions and diversities in a karst area
}

\author{
G Wang $\cdot$ Y Liu $\cdot$ M Cui $\cdot$ Z Zhou $\cdot \mathbf{Q}$ Zhang $\cdot$ \\ Y Li $\cdot$ W Ha $\cdot$ D Pang $\cdot \mathrm{J}$ Luo $\cdot \mathrm{J}$ Zhou
}

Published online: 6 November 2021

(C) Springer Nature Switzerland AG 2021

\section{Correction to: Plant Soil \\ https://doi.org/10.1007/s11104-021-05016-6}

The original version of this article unfortunately contained an incorrect designation of corresponding Author. Jinxing Zhou should be the sole CORRESPONDING AUTHOR for this publication per Author's request.

Publisher's note Springer Nature remains neutral with regard to jurisdictional claims in published maps and institutional affiliations.

The online version of the original article can be found at https://doi.org/10.1007/s11104-021-05016-6.

G. Wang $\cdot$ Y. Liu $\cdot$ M. Cui $\cdot$ Z. Zhou $\cdot$ Q. Zhang $\cdot$ Y. Li

W. Ha $\cdot$ D. Pang $\cdot$ J. Luo $\cdot$ J. Zhou $(\bowtie)$

Jianshui Research Station, School of Soil and Water

Conservation, Beijing Forestry University, Beijing 100083,

People's Republic of China

e-mail: zjx001@bjfu.edu.cn 